\title{
Thierry Poyet, Maxime Du Camp. L'Autre romancier
}

\section{Michel Arrous}

\section{(2) OpenEdition}

Journals

Édition électronique

URL : http://journals.openedition.org/studifrancesi/545

DOI : 10.4000/studifrancesi.545

ISSN : 2427-5856

\section{Éditeur}

Rosenberg \& Sellier

\section{Édition imprimée}

Date de publication : 1 avril 2015

Pagination : 176-177

ISSN : 0039-2944

\section{Référence électronique}

Michel Arrous, "Thierry Poyet, Maxime Du Camp. L'Autre romancier », Studi Francesi [En ligne], 175 (LIX I

I) | 2015, mis en ligne le 01 avril 2015, consulté le 18 septembre 2020. URL : http://

journals.openedition.org/studifrancesi/545; DOI : https://doi.org/10.4000/studifrancesi.545

\section{Ce document a été généré automatiquement le 18 septembre 2020}

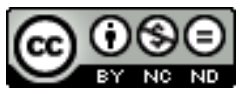

Studi Francesi è distribuita con Licenza Creative Commons Attribuzione - Non commerciale - Non opere derivate 4.0 Internazionale. 


\title{
Thierry Poyet, Maxime Du Camp. L'Autre romancier
}

\author{
Michel Arrous
}

\section{RÉFÉRENCE}

THIERRY POYET, Maxime Du Camp. L'Autre romancier, Paris, Éditions Kimé, 2013, pp. 322.

Pour l'auteur du Livre posthume (1853) et des Forces perdues (1867), ses deux romans les plus célèbres, la postérité n'a pas été tendre. Thierry Poyet, qui a réédité, préfacé et annoté le second de ces romans (Eurédit, 2011), est allé chercher Du Camp au fond du purgatoire où il "croupit" depuis plus d'un siècle, moins pour le réhabiliter que pour comprendre la décision de la postérité littéraire à l'égard de celui qui voulut être un autre écrivain que Flaubert. S'il n'est pas un deuxième Flaubert, Th. Poyet a clairement montré dans son édition que Du Camp n'est pas un romancier de second rang et que ce roman d'une désillusion que sont Les Forces perdues est représentatif de son temps. La cruelle question: «À quoi bon l'œuvre de Du Camp?» laisse entendre qu'il est vain de revenir sur la condamnation sans appel du personnage et de l'œuvre (les Goncourt, Maupassant, R. Dumesnil, A. Thibaudet, Sartre); pour autant Th. Poyet n'a pas cru inutile de revenir sur la sentence, non pas pour restaurer «la pauvre statue bien décrépite», mais pour comprendre comment un écrivain fort apprécié dans les années 1850 et 1860 a pu disparaître du champ littéraire et, simultanément, réfléchir aux conditions de la création artistique. Aussi n'est-il pas question des grands ouvrages historico-sociologique que Du Camp revendiquera alors qu'il ne défendra pas ses romans, ni de ses récits de voyage ou de sa critique d'art; son rôle de directeur de la «Revue de Paris» (1851-1858) est néanmoins opportunément mentionné. Pour redécouvrir Du Camp, «la face opposée de Flaubert», Th. Poyet propose un parcours dans l'œuvre qui repose sur une analyse de la stratégie d'un romancier qui s'était d'abord voulu poète. 
2 Est d'abord soulignée, dans les chap. 2 et 3, la dimension autobiographique des deux romans dans lesquels on peut voir une biofiction avant l'heure. Leur construction est précisée et leur réception critique reconstituée. En bon avocat, Th. Poyet se demande pourquoi et comment les personnages romanesques de Du Camp, inconsistants dans la mesure où ils n'existent pas en tant que héros - dans Les Forces perdues, le romantique Horace Darglail «s'évanouit à lui-même» (p. 95) - ont rencontré un lectorat et ont été bientôt oubliés. Quelle a été la clef de ce succès temporaire et comment expliquer cet échec définitif? Le personnage ducampien doit être saisi «dans la réalité qui est la sienne au moment où il apparaît sur la scène littéraire». L'analyse relève d'innombrables faiblesses (personnage trop peu singulier, réalisme photographique, défaut d'ancrage historique, tics d'écriture, aucune peinture du contexte), et surtout, de la part de l'auteur, l'habitude de raconter peu ou prou la même histoire, et une propension si constante à se prendre pour modèle qu'on peut légitimement parler, comme chez Houellebecq souvent cité, d'une dimension autofictionnelle (chap. 4). Les chapitres 5 et 6 sont consacrés à la scénographie auctoriale de Du Camp, à sa conception de l'écrivain, en partie partagée par Flaubert, et à ses exigences esthétiques, fondées sur l'utilité de l'art et quelque peu compromises par son souci de la réussite, même si l'on ne doit pas réduire Du Camp au seul souci de la réussite éditoriale. La différence capitale entre Du Camp et Flaubert, c'est que le premier pense que l'écrivain écrit pour un public dont il convient de tenir compte, alors que pour le second la littérature ne peut être qu'autotélique. Sur ce point, la rupture des deux amis est totale. Suivent deux chapitres consacrés à un autre versant de l'œuvre littéraire de Du Camp: il s'agit d'œuvres fort peu connues car elles n'ont pas été rééditées, ou d'œuvres mal interprétées. D'abord quatre recueils de nouvelles (1857, où figure Tagahor, qui plut beaucoup à Flaubert, 1862, 1866 et 1893) dans lesquels, bien qu'il n'innove guère dans les thèmes par rapport à ses deux grands romans, Du Camp fait preuve d'un véritable talent de nouvelliste; puis deux courts romans en 1862 et 1888 - Une Histoire d'amour mériterait d'être réédité. Ensuite, il y a le poète qui voulut révolutionner la littérature avec ses Chants modernes (1855 et 1860), sévèrement accueillis mais dont la préface, où Du Camp réglait ses comptes avec l'Académie (il en sera vingt-cinq ans plus tard) et les tenants de «l'Art pour l'Art», fut plus remarquée que les poésies. Le recueil fut mal lu, ou, encore récemment, selon une optique partielle qui oublie que les fameux «Chants de la matière» ne comptent que cinq pièces. Th. Poyet signale son «unité faussement cohérente» et note que, loin de la pétition moderniste de la préface qui se voulait un manifeste en faveur du progrès et de la science, Du Camp se soucie moins de son époque que de ses états d'âme. Force est de constater qu'il n'a pas révolutionné grandchose. Il récidivera en 1858 avec Les Convictions (discrètement dédicacées à Valentine Delessert) où le lyrisme et l'épanchement l'emportent. Sans doute Du Camp a-t-il fini par comprendre que la poésie ne permettait pas de rencontrer un large public; pourtant, il a continué à la fréquenter ou plutôt à fréquenter Baudelaire, Nerval, Louise Collet ou Bouilhet en tant que directeur de revue. Seuls ont survécu dans son estime, Musset, un amour de jeunesse, et Gautier auquel il consacra un volume hagiographique en 1890, mais ce n'est pas le Gautier de «l'Art pour l'Art», trop proche de Flaubert!

3 Nul ne s'étonnera du titre du dernier chapitre: «Lire Du Camp maintenant ou l'oublier à jamais» (pp. 247-286). Aux causes de désaffection repérées en 1983 par K. Kouassi, Th. Poyet, qui n'oublie pas que Du Camp fut l'ami scandaleux qui révéla l'épilepsie de Flaubert, en ajoute de plus déterminantes, notamment son incapacité à se renouveler et, surtout, sa conception de la littérature qui fait de l'écrivain le porte-parole d'un 
message, un artisan et non un artiste, «diamétralement opposé au type flaubertien». C'est fort pertinemment qu'il invite ses lecteurs à s'interroger sur «la double thématique de la postérité littéraire et d'un rapport actuel à la littérature du XIX siècle en train de se complexifier» (p. 278). Le cas de Du Camp, «mal lu ou plus lu du tout» comme tant d'autres, permet de comprendre ce revers de médaille, mais plus encore met en cause notre responsabilité de lecteurs face à la production littéraire du siècle. 